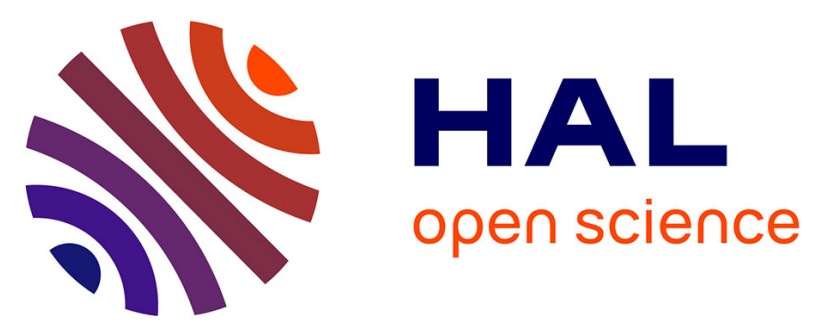

\title{
Megakaryocyte-restricted MYH9 inactivation dramatically affects hemostasis while preserving platelet aggregation and secretion.
}

Catherine Léon, Anita Eckly, Béatrice Hechler, Boris Aleil, Monique Freund, Catherine Ravanat, Marie Jourdain, Christelle Nonne, Josiane Weber, Ralph Tiedt, et al.

\section{To cite this version:}

Catherine Léon, Anita Eckly, Béatrice Hechler, Boris Aleil, Monique Freund, et al.. Megakaryocyterestricted MYH9 inactivation dramatically affects hemostasis while preserving platelet aggregation and secretion.: Role of myosin IIA in hemostasis and thrombosis. Blood, 2007, 110 (9), pp.3183-91. 10.1182/blood-2007-03-080184 . inserm-00166437

\section{HAL Id: inserm-00166437 https://www.hal.inserm.fr/inserm-00166437}

Submitted on 24 Jul 2008

HAL is a multi-disciplinary open access archive for the deposit and dissemination of scientific research documents, whether they are published or not. The documents may come from teaching and research institutions in France or abroad, or from public or private research centers.
L'archive ouverte pluridisciplinaire HAL, est destinée au dépôt et à la diffusion de documents scientifiques de niveau recherche, publiés ou non, émanant des établissements d'enseignement et de recherche français ou étrangers, des laboratoires publics ou privés. 


\section{HAL author manuscript}

Megakaryocyte-restricted MYH9 inactivation dramatically affects hemostasis while preserving platelet aggregation and secretion.

Catherine Léon ${ }^{1}$, Anita Eckly ${ }^{1}$, Béatrice Hechler ${ }^{1}$, Boris Aleil ${ }^{1}$, Monique Freund ${ }^{1}$, Catherine Ravanat $^{1}$, Marie Jourdain ${ }^{1}$, Christelle Nonne ${ }^{1}$, Josiane Weber ${ }^{1}$, Ralph Tiedt ${ }^{2}$, Marie-Pierre Gratacap $^{3}$, Sonia Severin ${ }^{3}$, Jean-Pierre Cazenave ${ }^{1}$, François Lanza ${ }^{1}$, Radek Skoda ${ }^{2}$ and Christian Gachet ${ }^{1}$

${ }^{1}$ INSERM, U311, Strasbourg, France; EFS-Alsace, Strasbourg, France; Université Louis Pasteur, Strasbourg, UMR-S311, France.

${ }^{2}$ Department of Research, Experimental Hematology, University Hospital Basel, 4031 Basel, Switzerland.

${ }^{3}$ INSERM, U563, Centre de Physiopathologie de Toulouse, Département d'Oncogenèse et Signalisation dans les Cellules Hématopoïétiques, Toulouse, France; Université Toulouse III Paul Sabatier, Faculté de médecine Toulouse-Purpan, UMR-S563, Toulouse, France.

This study was supported by ARMESA (Association de Recherche et Développement en Médecine et Santé Publique) and Fondation de France (2007001964). C.L. and B.H. are supported by a "contrat d'interface" between EFS and INSERM.

Running head: Role of myosin IIA in hemostasis and thrombosis

Total text word count: 4886

Abstract word count: 199

\section{Correspondence to:}

C. LEON or Dr C. GACHET

INSERM U.311, Etablissement Français du Sang-Alsace (EFS-Alsace)

10, rue Spielmann, B.P. $N^{\circ} 36$

67065 Strasbourg Cedex, France

Tel: (33) $388212525 \quad$ Fax: (33) 388212521

e-mail: catherine.leon@efs-alsace.fr or christian.gachet@efs-alsace.fr 
Scientific category: Hemostasis, Thrombosis, and Vascular Biology

\section{Author's contribution statement}

C. Leon designed and performed research, analyzed data and wrote the paper
A. Eckly performed and analyzed electron microscopy imaging
B. Hechler, M. Jourdain and C. Nonne performed and analysed in vitro thrombus formation and in vivo experimental thrombosis

C. Ravanat and B. Aleil designed and analysed flow cytometry experiments

M. Freund took care about the animals and performed animal experimentation

J. Weber constructed MYH9 knockout mice

M-P. Gratacap and S. Severin performed and analysed phospholipids measurements

R. Tied and R. Skoda contributed with PF4-cre mice

J.-P. Cazenave discussed results

F. Lanza discussed results and wrote the paper

C. Gachet designed research, analysed the data and wrote the paper 


\begin{abstract}
Mutations in the MYH9 gene encoding the non-muscle myosin heavy chain-IIA result in bleeding disorders characterized by a macrothrombocytopenia. To understand the role of myosin in normal platelet functions and in pathology, we generated mice with disruption of MYH9 in megakaryocytes. MYH9S mice displayed macrothrombocytopenia with a strong increase in bleeding time and absence of clot retraction. However, platelet aggregation and secretion in response to any agonist were near normal despite absence of initial platelet contraction. By contrast, integrin outside-in signaling was impaired, as observed by a decrease in integrin $\beta 3$ phosphorylation and $\operatorname{PtdIns}(3,4) \mathrm{P}_{2}$ accumulation following stimulation. Upon adhesion on a fibrinogen-coated surface, MYH9S platelets were still able to extend lamellipodia but without stress fiber-like formation. As a consequence, thrombus growth and organization, investigated under flow by perfusing whole blood over collagen, were strongly impaired. Thrombus stability was also decreased in vivo in a model of $\mathrm{FeCl}_{3}$-induced injury of carotid arteries. Overall, these results demonstrate that while myosin seems dispensable for aggregation and secretion in suspension, it plays a key role in platelet contractile phenomena and outside-in signaling. These roles of myosin in platelet functions, in addition to thrombocytopenia, account for the strong hemostatic defects observed in MYH9D mice.
\end{abstract}




\section{Introduction}

Important morphological changes occur in platelets during their activation at sites of vascular injury. The cells loose their resting discoid shape to become spheroid and contracted, emitting membrane blebs and longer extensions ${ }^{1-4}$. Once in contact with a surface, the spheroid platelets extend long filopodia and finally spread over it by emitting thin, sheet-like lamellipodia ${ }^{1,2}$. Myosin activation plays a central role in the cytoskeletal rearrangements underlying these changes in morphology. Myosin becomes activated after phosphorylation of the myosin regulatory light chain (RLC), which results from both calcium-regulated myosin light chain kinase activity and Rho kinase-regulated myosin phosphatase activity ${ }^{5-8}$. Activated myosin assembles into short filaments through the myosin heavy chain and interacts mainly with central actin filaments. Myosin has been proposed to participate in several platelet contractile functions such as platelet spheration, contraction and stress fiber formation, and fibrin clot retraction. Platelet spheration and contraction as observed in the aggregometer closely correlate with phosphorylation of the RLC ${ }^{9,10}$ and are prevented when RLC phosphorylation is inhibited ${ }^{6,7,9,10}$. Myosin has also been shown to be associated with stress fiber-like structures in spreading adherent platelets ${ }^{11}$. In addition, myosin could play a role in platelet secretion as it is decreased by inhibition of myosin RLC phosphorylation ${ }^{5,12-15}$. Finally, a role of myosin in clot retraction has long been suspected in view of the necessity for a contractile force and was recently confirmed using a direct inhibitor of myosin activity ${ }^{16}$.

Several of these platelet functions are altered in patients carrying mutations in the MYH9 gene encoding the non-muscle myosin heavy chain IIA (NMHC-IIA) which is the only myosin heavy chain isoform present in platelets ${ }^{17}$. Mutations in this gene are responsible for the so-called MYH9-related disorders, which encompass several autosomal dominant diseases previously classified as May-Hegglin anomaly, Fechtner syndrome, Sebastian syndrome or Epstein syndrome ${ }^{18-20}$. Different mutations have been reported that in all cases result in 
abnormal NMHC-IIA. All these patients share the triad of thrombocytopenia, large platelets and characteristic leukocyte inclusions (Döhle-like bodies) composed of ribosomes, endoplasmic reticulum and abnormal myosin aggregates ${ }^{21,22}$. Platelets from these patients fail to undergo shape change in the aggregometer in response to agonists but display normal aggregation ${ }^{18,23-25}$. While most patients are asymptomatic or have a mild bleeding tendency, a few suffer from significant bleeding, either spontaneously or during childbirth or surgical procedures ${ }^{26}$. Other manifestations may occur such as cataracts, sensorineural deafness or nephritis, which is consistent with the wide tissue expression of NMHC-IIA. Most of these other manifestations appear later during adulthood, probably because of the presence of other heavy chain isoforms in the tissues involved that compensate for the abnormal NMHC-IIA 20,27,28. The molecular mechanisms leading to the platelet abnormalities are still subject to debate. Some studies suggested that mutations in MYH9 led to a dominant negative effect, "poisoning" the wild-type myosin ${ }^{21,29}$, others showed that the disease resulted from a haploinsufficiency ${ }^{30}$ and a more recent study suggested haploinsufficiency in the megakaryocytic lineage associated with a dominant negative effect in granulocytes ${ }^{31}$.

To explore the role of myosin and the effects of myosin deficiency on the hemostatic functions of platelets, we generated mice with disruption of MYH9. Since previous studies have shown early embryonic mortality in MYH9-/- mice ${ }^{28,32}$ (and unpublished data), we used the loxP-Cre system to restrict the MYH9 knock out to the megakaryocyte lineage. Mice carrying a floxed MYH9 first exon were crossed with transgenic mice carrying crerecombinase under the regulation of the platelet PF4 promoter ${ }^{33}$. Inactivation of MYH9 in megakaryocytes resulted in a severe defect in platelet myosin expression with a phenotype resembling that of MYH9-related diseases, including thrombocytopenia, large and immature platelets and impaired platelet contractile activity. Our data show that whereas platelet aggregation and secretion responses were only moderately affected, myosin deficiency led to 
dramatically disturbed primary hemostasis with severely prolonged tail bleeding times and a total absence of clot retraction. The platelet contractile shape change and outside-in signaling were affected, inhibiting thrombus growth in vitro under flow and in vivo following vessel wall injury. 


\section{Materials and Methods}

Materials. Equine tendon collagen was from Nycomed (Germany) and human fibrinogen from Kabi (Sweden). BSA, Busulfan, thrombin and anti-NMHC-IIA antibody were from Sigma-Aldrich (France). Blebbistatin was from Calbiochem (VWR, France). Eptifibatid was from GlaxoSmithKline. Jon/A-PE antibody, FITC-labeled anti-fibrinogen antibody, antiCD41/CD61-PE and anti-CD61 ( $\beta 3$ integrin) antibodies were from Emfret (Germany). Anti$\beta 3$ integrin [pY773] phosphospecific antibody was from Biosource International, Inc. (USA), anti-myosin RLC from Santa Cruz (USA) and the ECL kit from Amersham, Pharmacia Biotech (France). Phalloidin-Alexa Fluor 488 and goat anti rabbit-Alexa Fluor 488 antibody were from Molecular Probe (Invitrogen, France). Complete Protease Inhibitor Cocktail was from Roche Diagnostics (France).

Generation of megakaryocyte-restricted MYH9D mice. The contruction of floxed ES cells is detailed in supplementary figure 1 . Floxed heterozygous mice (50\% C57BL/6-50\% 129sv) were crossed with transgenic mice selectively expressing cre-recombinase in the megakaryocyte lineage, under control of the BAC PF4 (platelet factor 4) promoter (100\% C57BL/6) ${ }^{33}$. Mice expressing cre gene and heterozygous for the MYH9 recombination were intercrossed to obtain littermate mice homozygous for the wild-type (WT) MYH9 allele (+/+ mice) and homozygous for the recombined allele (MYH9S or -/- mice), or heterozygotes (+/mice).

Bleeding time. Male and female mice (20-25g) were anesthetized by inhalation of isoflurane. The extremity of the mouse tail was cut transversally with a scalpel $(3 \mathrm{~mm})$ and immediately immersed in $0.9 \%$ isotonic saline at $37^{\circ} \mathrm{C}$. The bleeding time was defined as the time required 
for arrest of bleeding and when necessary bleeding was stopped manually at the 10 min time point to prevent death.

Clot retraction. Citrated PRP (adjusted to $3.10^{5}$ platelets $/ \mu \mathrm{L}, 300 \mu \mathrm{L}$ ) obtained by centrifugation of whole blood at $250 \mathrm{~g}$ for 10 minutes was stimulated with thrombin (10 $\mathrm{U} / \mathrm{mL})$ in the presence of $\mathrm{CaCl}_{2}(20 \mathrm{mM})$ and incubated at $37^{\circ} \mathrm{C}$ for up to 5 hours, together with $2 \mu \mathrm{L}$ of erythrocytes to enhance the contrast of the clot.

Platelet survival. Platelet survival time was determined using a modified method adapted from Peng et al. ${ }^{34}$ by in vivo biotinylation of platelets through intravenous injection of sulfoNHS-Biotin (twice $2 \mathrm{mg} / \mathrm{kg}$ with 30 minutes interval, 5 mice of each genotype). Biotinylated platelets were counted daily for 4 days at 7 hour intervals. The percentage of biotinylated platelets was determined using flow cytometry by double labeling of whole blood with streptavidin-PE $(100 \mu \mathrm{g} / \mathrm{mL})$ and anti-CD41/CD61-PE.

Platelet activation studies. Blood was drawn from the abdominal aorta, platelets were washed and aggregation performed as described ${ }^{35}$. Platelet shape change was visualized by the decrease in light transmission in the absence of fibrinogen and in the presence of Eptifibatid (40 $\mu \mathrm{g} / \mathrm{mL}$ ) to prevent aggregation. Dense granule release was evaluated by the measure of serotonin secretion in platelets loaded with ${ }^{3} \mathrm{H}-5 \mathrm{HT}$. In some cases, platelets were pretreated with blebbistatin $(100 \mu \mathrm{M})$ for 30 minutes. Static adhesion assays were performed as previously described ${ }^{36}$. Briefly, coverslips were coated with fibrinogen $(100 \mu \mathrm{g} / \mathrm{mL})$, blocked with BSA $(5 \mathrm{mg} / \mathrm{mL})$ and washed. Platelet suspensions $\left(2 \times 10^{4}\right.$ platelets $\left./ \mu \mathrm{L}\right)$ were stimulated with thrombin $(1 \mathrm{U} / \mathrm{mL})$, immediately plated onto the coverslips and incubated at $37^{\circ} \mathrm{C}$ for 45 $\min$. 
Immunofluorescence. Paraformaldehyde (2\%) fixed platelets were permeabilized with $0.05 \%$ saponin in the presence of $0.2 \%$ bovine serum albumin, incubated with phalloidin-AF 488 or a primary antibody (anti NMHC-IIA, dilution 1/500) followed by a secondary antibody (goat anti rabbit-AF 488). The cells were observed under a confocal microscope (Leica TCS SP5, Leica Microsystems, France) with oil objectif (APO 100x, 1.30 NA). Surface area was quantified using Methamorph ${ }^{\mathrm{TM}}$ software (Version 5; Universal Imaging Corporation, Downingtown, PA).

Flow cytometry. The activation state of the integrin $\alpha \operatorname{Ilb} \beta 3$ was measured in washed platelets stimulated for 10 minutes with either collagen $(100 \mu \mathrm{g} / \mathrm{mL})$ or thrombin $(1 \mathrm{U} / \mathrm{mL})$ without stirring, followed by labeling with Jon/A-PE $(1 / 20)^{37}$ or FITC-labeled anti-fibrinogen antibody $(1 / 20)$. The extent of integrin activation was determined for both antibodies by the geometric mean of the relative fluorescence intensity of the whole platelet population (in arbitrary units).

Western blotting. Frozen ground tissues lysates were prepared in 1\% Triton X100 buffer. Platelet lysates were prepared by resuspending washed platelets $\left(3 \times 10^{5} / \mu \mathrm{L}\right)$, activated or not by thrombin $(1 \mathrm{U} / \mathrm{mL})$ for various times, in SDS buffer (1\% SDS final concentration). Proteins were separated by SDS-PAGE under reducing conditions, transferred to PVDF membranes and incubated with the primary antibody (antibody directed against NMHC-IIA, RLC, actin, $\beta 3$ integrin or phosphorylated $\beta 3$ integrin). Quantification was performed using the ImageQuant TL software v2003.03 (Amersham Biosciences). The amount of phosphorylated $\beta 3$ integrin was normalized against total $\beta 3$ integrin, and the NMHC-IIA was normalized against actin. 
Lipid extraction and analysis. Platelets were labeled with $22 \mathrm{GBq} / \mathrm{ml}\left[{ }^{32} \mathrm{P}\right]$ orthophosphate during $45 \mathrm{~min}$ in a phosphate-free washing buffer $(\mathrm{pH} 6.5)^{38}$ at $37^{\circ} \mathrm{C}$, washed once and suspended at a final concentration of $5 \times 10^{5}$ platelets $/ \mu 1(\mathrm{pH} 7.38)$. After stimulation, reactions were stopped by addition of chloroform/methanol $(1 / 1, \mathrm{v} / \mathrm{v})$ containing $0.4 \mathrm{~N} \mathrm{HCl}$, and lipids were immediately extracted and quantified as described ${ }^{38}$.

Electron microscopy. Platelets were fixed directly in the aggregometer cuvette with $2.5 \%$ glutaraldehyde in $0.1 \mathrm{M}$ cacodylate buffer, $\mathrm{pH} 7.2$, containing $2 \%$ sucrose. Cells for transmission electron microscopy (TEM) were processed as described previously ${ }^{35}$ and ultrathin sections were examined under a Philips CM120 Biotwin electron microscope (FEI, Eindhoven, The Netherlands) at $120 \mathrm{kV}$. Scanning electron microscopy (SEM) was performed as described elsewhere ${ }^{37}$ under a Sirion scanning electron microscope (FEI) at $5 \mathrm{kV}$.

In vitro model of thrombosis on immobilized collagen under flow conditions. Platelet thrombus formation was studied as described previously ${ }^{39}$. Control wt mice were injected intraperitoneously with busulfan $(30 \mathrm{mg} / \mathrm{kg}) 14$ days before drawing blood so as to obtain a thrombocytopenia ranging from $1.10^{5}$ to $3.10^{5}$ platelets/ $\mu \mathrm{L}$. MYH9S mice were injected with vehicle (polyethylene-glycol). Hirudin anticoagulated whole blood was perfused through collagen-coated glass capillaries at a shear rate of 3,000 s ${ }^{-1}$. For SEM analysis, the capillaries were rinsed with saline after blood perfusion for 2 minutes and the surface was fixed with $2.5 \%$ glutaraldehyde in $0.1 \mathrm{M}$ cacodylate buffer $(\mathrm{pH} 7.2)$. The capillaries were sectioned longitudinally, treated and examined as described previously ${ }^{40}$.

$\mathrm{FeCl}_{3}$-induced carotid artery thrombosis. Carotid artery injury was performed by topical application of $\mathrm{FeCl}_{3}$ for 2 minutes (Whatmann paper $1 \times 0.5 \mathrm{~mm}$ soaked with $0.2 \mu \mathrm{L}$ of $7.5 \%$ $\mathrm{FeCl}_{3}$ ). The artery was then rinsed with saline and the thrombus growth was monitored for 20 
minutes. DIOC6 (5 $\mu \mathrm{L}$ of a $100 \mu \mathrm{M}$ solution/g of body weight) was injected into the jugular vein prior to injury to allow visualization of the thrombus surface. The carotid was placed under a fluorescent macroscope (Macrofluo ${ }^{\mathrm{TM}}$, Leica Microsystems, Rueil-Malmaison, France) for video recording of thrombosis ${ }^{41}$. Fluorescent images were acquired sequentially (1 image/s) using a CoolSNAP EZ camera (Ropper Scientific, Evry, France) controlled by Metaview software (Universal Imaging Corporation, Downingtown, PA). Quantification of embolism was performed using Metamorph ${ }^{\mathrm{TM}}$ software. A region of interest was delineated downstream of the thrombus. Emboli surface was expressed as the total number of fluorescent pixels inside the region of interest, measured at each time.

Statistics. The results are expressed as mean \pm sem. The significance of the differences between genotypes was evaluated using Student t-test or Student Paired t-test, as mentioned. 


\section{Results}

\section{Generation of megakaryocyte-specific MYH9А mice}

In order to generate a viable animal model with NMHC-IIA deficiency in the megakaryocytic lineage, we ablated exon 1 from the MYH9 gene using a PF4-promoter driven Cre-loxP system. Exon 1 was excised in vivo (MYH9A) by crossing MYH9 ${ }^{F l x / F l x}$ mice with transgenic animals expressing cre-recombinase specifically in megakaryocytes under the control of the PF4 promoter ${ }^{33}$. MYH9 ${ }^{F l x / w t}$; PF4-cre mice were intercrossed to produce platelet-specific NMHC-IIA deficient mice (Figure 1a and supplementary data), which were obtained in a mendelian ratio and were healthy, with no gross abnormality.

\section{MYH9A mice exhibit severe NMHC-IIA deficiency}

To determine the extent and tissue specificity of the NMHC-IIA deficiency, lysates from platelets and several tissues were analyzed by Western blotting. Normal myosin content was detected in kidney, lung, liver and spleen of MYH9D mice (Figure 1b). In contrast, a severe myosin deficiency was found in platelets where the residual myosin amounted to less than 3\% of control platelets (Figure 1c, upper panel). The anti-myosin antibody being directed against the C-terminal part of the protein, this indicated that disruption of the first exon suppressed synthesis of most of the entire protein. A band of slightly lower molecular mass was also observed in MYH9 $\Delta$ platelets only. This band could correspond to residual NMHCIIA deleted from exon one since it is not observed in control platelets. The myosin regulatory light chain content was likewise considerably decreased in MYH9S platelets, probably due to its instability in the absence of NMHC-IIA (Figure 1c, lower panel) ${ }^{42,43}$. Platelet expression of the residual NMHC-IIA was visualized by immunofluorescence microscopy. As seen in 
Figure 1d, the intensity of NMHC-IIA labeling was considerably reduced in all MYH9D platelets compared to control.

\section{MYH9A mice display thrombocytopenia and altered platelet morphology}

Mice deficient in NMHC-IIA reproduced some of the characteristic features of MYH9related diseases in humans. These mice exhibited thrombocytopenia with an average platelet count representing around $40 \%$ of wild-type (wt: $1028 \pm 63 \times 10^{3}$ platelets $/ \mu \mathrm{L}$, heterozygous: $890 \pm 41 \times 10^{3}$ platelets $/ \mu \mathrm{L}$, MYH9 $: 336 \pm 28 \times 10^{3}$ platelets $/ \mu \mathrm{L}$ ) (Figure $2 \mathrm{a}$ ). The decreased platelet count in heterozygote mice was not statistically different as compared to wt. These mice also presented an altered platelet morphology with a mean size around twice that of controls as determined by transmission electron microscopy performed on buffy coats (platelet area: $1.8 \pm 0.1(\mathrm{n}=215)$ vs $4.4 \pm 0.2 \mu \mathrm{m}^{2}(\mathrm{n}=190)$ for control and MYH9D platelets respectively, $\mathrm{p}<0.0001$, unpaired t-test) or by whole blood flow cytometry (FSC Geometric Mean of $\alpha_{\text {IIb }} \beta_{3}$-positive population: $15.1 \pm 1.3$ for control mice $v s 26.8 \pm 0.9$ for $M Y H 9 \Delta$ mice, $\mathrm{n}=5, \mathrm{p}<0.0001$ using unpaired t-test) (Figure $2 \mathrm{~b}$ and $2 \mathrm{c}$ ). Ultrastructural analysis of MYH9S washed platelets revealed some heterogeneity with a mixed population of normal discoid and more ovoid morphology, compared to the control platelets (Figure $2 \mathrm{~b}$ and 2c). A large proportion of these platelets contained large amounts of rough endoplasmic reticulum (RER), typical of young or immature cells as observed both by electron microscopy $(15.3 \%$ of MYH9D platelets vs. $0.5 \%$ of wt platelets, respectively) (Fig. 2d) and thiazole orange labeling (data not shown). Ultrastructure of platelets from heterozygous animals appeared normal (data not shown). There was no defect in expression of some major platelet glycoproteins $\left(\alpha_{\text {IIb }} \beta_{3}\right.$, GPIb $\alpha$, GPIb $\beta$, GPV) as detected by flow cytometry (data not shown).

In vivo platelet half-life was similar in the two genotypes (survival time: $112.4 \pm 6.1 \mathrm{vs}$ 101.6 \pm 4.6 hours for wt and MYH9 $\Delta$ mice, respectively, $\mathrm{n}=5, \mathrm{p}>0.05$ ), suggesting that the 
thrombocytopenia does not result from an accelerated clearance from the circulation and that the increased proportion of reticulated cells mostly reflects a defect in the formation of mature platelets.

\section{MYH9А mice exhibit a strong increase in bleeding time and a total absence of clot retraction}

MYH9S mice presented no evidence of spontaneous bleeding or hemorrhage. Tail bleeding times were performed to explore primary hemostasis functions following injury. Control wt mice had an average bleeding time of $78 \pm 16$ s (Fig. 3a). An increased bleeding time up to $400 \mathrm{~s}$ was observed in some heterozygous mice but the average bleeding time was not significantly different from the wt $(135 \pm 39$ s). By contrast, all the MYH9S mice bled for more than $600 \mathrm{~s}$. It is noteworthy that the bleeding was so important in these mice that they died by 20 minutes unless the wound was manually cauterized (data not shown). By comparison, busulfan-induced thrombocytopenia in wt mice (ranging from 0.3 to $0.6 \times 10^{6}$ platelets $/ \mu \mathrm{L}$ which is comparable to MYH9 $\Delta$ mice) did not significantly affect the bleeding time $(173 \pm 24 \mathrm{~s})$ (Figure 3a).

Clot retraction, a platelet-dependent contractile phenomenon important for thrombus consolidation, was then investigated. No retraction at all was observed in clots of myosindeficient platelets 5 hour post-thrombin activation, while maximal retraction was observed for the wt platelets (Figure 3b). Heterozygous mice exhibited an intermediate phenotype, the retraction being delayed as compared to the wt (Figure 3b).

Thus an intrinsic platelet function defect accounts for this bleeding phenotype independently of the thrombocytopenia.

Platelet aggregation and secretion are barely affected by myosin deficiency 
The defective hemostasis in MYH9S mice led us to investigate in vitro platelet aggregation in response to different concentrations of ADP, thrombin, collagen and U46619. The velocity and amplitude of aggregation were similar in MYH9S and control platelets except at the lowest concentration of thrombin $(0.02 \mathrm{U} / \mathrm{mL})$ and $\mathrm{U} 46619(0.5$ and $0.1 \mu \mathrm{M})$ where a decreased aggregation was observed (Figure 4a). The transient decrease in light transmission which reflects platelet spheration (circled in the figure 4a) was absent in MYH9A cells, whatever the agonist. Release of $\left[{ }^{3} \mathrm{H}\right]$ serotonin from dense granules was barely decreased in MYH9S platelets after stimulation with collagen or high concentrations of thrombin but more reduced after activation with U46619 or low concentrations of thrombin (Table 1). Altogether, there appears to be a minor impact if any of myosin-deficiency on platelet aggregation and secretion in suspension. In order to assess whether the residual myosin expression could play a part in the near normal aggregation and secretion observed, platelets were pretreated with blebbistatin $(100 \mu \mathrm{M})$, an inhibitor of non-muscle myosin II

activity ${ }^{44,45}$. Under these conditions, blebbistatin totally prevented initial platelet shape change in control platelets. However, no further inhibition of platelet aggregation or secretion was observed in MYH9D platelets (data not shown). Thus, these data show that myosin does not play a crucial role in these functions.

Myosin-deficient platelets display impaired contractile shape change and stress fibers formation

Platelet shape change was further investigated in the aggregometer following addition of $5 \mu \mathrm{M}$ ADP in the absence of fibrinogen and in the presence of the integrin $\alpha_{\mathrm{IIb}} \beta_{3}$ antagonist Eptifibatid to prevent platelet aggregation. As shown in Figure $4 b$, the shape change was almost abolished in MYH9S as compared to control platelets while platelets from heterozygous mice exhibited normal shape change (data not shown). Observation by SEM 
revealed the presence of $92 \%$ discoid platelets with only a few or no membrane extensions whereas in the control $72 \%$ of the platelets underwent rounding and contraction (Figure $4 \mathrm{~b}$ ). Platelets from heterozygous animals behaved similarly to the control platelets (data not shown). Treatment of platelets with blebbistatin abolished rounding and contraction of control platelets by $96 \%$ and had no further significant effect on MYH9D platelets (data not shown).

Platelet spreading and stress fibers formation were then studied during adhesion of platelets to a fibrinogen-coated surface. When pre-stimulated with thrombin, both wt and MYH9D platelets were able to adhere to the surface and extend lamellipodia, as was revealed by phalloidin labeling of actin fibers (Figure 5a) and SEM after triton X100 permeabilization (Figure 5b). However, MYH9D platelets were unable to form stress fiber-like structures contrary to control platelets. Instead, long actin filaments were observed throughout the cytoplasm together with short filaments at the leading edge, and the final mean surface area was increased by $10 \%$ ( $\mathrm{n}=736$ and 670 platelets for control and MYH9S platelets, respectively, $\mathrm{p}<0.0002$ using Student t-test).

\section{Outside-in signaling is strongly impaired in myosin-deficient platelets}

The absence of stress fibers formation on a fibrinogen matrix together with absent clot retraction prompted us to evaluate signaling through integrin $\alpha \operatorname{Ilb} \beta 3$. Integrin activation was evaluated in control and MYH9S mice following activation by collagen $(100 \mu \mathrm{g} / \mathrm{mL})$ or thrombin $(1 \mathrm{U} / \mathrm{mL})$ in the absence of stirring. The level of activated integrin was measured by flow cytometry using an antibody directed against the activated form of the integrin (Jon/A PE antibody ${ }^{37}$ ) or against integrin-bound fibrinogen. In both cases, thrombin stimulation led to a significant decrease in $\alpha \operatorname{IIb} \beta 3$ activation that was not observed with collagen (Figure $6 a$ ).

Outside-in signaling was then evaluated by the phosphorylation of the integrin $\beta 3$ during the course of thrombin-induced platelet aggregation. As shown by immunoblotting, 
thrombin stimulation led to the phosphorylation of integrin $\beta 3$ as early as 60 seconds following agonist addition in control platelets. By contrast, in MYH9S platelets, there was impairment in the phosphorylation of the integrin. By 3 minutes, the amount of integrin $\beta 3$ phosphorylated in myosin-deficient platelets was decreased by $65 \%$ as compared to the wt platelets, indicating that myosin plays a role in integrin outside-in signaling (Figure 6b).

To further evaluate defective outside-in signaling, we measured the activity of PI 3kinase. Particularly, the synthesis of a major part of one of its product, $\operatorname{PtdIns}(3,4) \mathrm{P}_{2}$, is indeed dependent upon the engagement of the integrin ${ }^{46,47}$. The levels of $\operatorname{PtdIns}(3,4) \mathrm{P}_{2}$ and PtdIns $(3,4,5) \mathrm{P}_{3}$ were measured following platelet stimulation by thrombin or collagen. While the levels of PtdIns(3,4,5) $\mathrm{P}_{2}$ were comparable between the two genotypes (not shown), $\operatorname{PtdIns}(3,4) \mathrm{P}_{2}$ accumulation was reduced by $70 \%$ in MYH9D platelets (Figure $6 \mathrm{c}$ ), consistent with a defect in outside-in signaling.

\section{Thrombus organization is impaired in vitro under flow conditions and in vivo}

To evaluate the role of myosin in the process of thrombus formation, we first investigated thrombus growth in vitro in a whole blood perfusion assay over a fibrillar collagen matrix under arterial shear rate conditions $\left(3,000 \mathrm{~s}^{-1}\right)^{48}$. Keeping in mind the decreased platelet count in MYH9S mice, wt mice were treated with busulfan to reach thrombocytopenia levels comparable to that of MYH9 $\Delta$ mice $\left(290 \pm 115 \times 10^{3}\right.$ platelets $/ \mu \mathrm{L}$ for busulfan-treated mice, and $220 \pm 103 \times 10^{3}$ platelets $/ \mu \mathrm{L}$ for $M Y H 9 \Delta$ mice). After 2 min perfusion, analysis of the flow chamber by SEM revealed that the structure of the thrombi was totally different between both genotypes. In the control condition, the compact aggregates formed were composed of contracted platelets tightly packed together. In contrast, aggregates of MYH9 $\Delta$ blood contained only a few layers of platelets that did not have contracted bodies 
and were rather flat with spread morphology, and were loosely packed as compared to the control cells (Figure 7a).

The capacity of MYH9D mice to develop a thrombus was then evaluated in vivo in a carotid artery thrombosis model where injury was induced by topical application of $\mathrm{FeCl}_{3}$ and visualized by intravital microscopy ${ }^{41}$ (Figure $7 \mathrm{~b}$ and supplemental videos). Busulfan-treated wt mice were used as control. These mice exhibited a platelet count of $312 \pm 57 \times 10^{3}$ platelets $/ \mu \mathrm{L}(\mathrm{n}=8)$ similar to platelet counts in $M Y H 9 \Delta$ mice used in this experiment $(317 \pm 76$ $\mathrm{x} 10^{3}$ platelets $\left./ \mu \mathrm{L}\right)$. In control mice, the thrombus was compact and occupied the whole injured surface as judged by the uniform intensity of fluorescence. By contrast, in MYH9D mice, the injured surface was not uniformly covered as observed by the lack of homogeneity of the fluorescence, indicating that platelets were not tightly packed and that the thrombus did not grow in height (Figure $7 \mathrm{~b}$ and supplemental videos S1 and S2). In addition, large emboli were continuously detaching from the thrombus of MYH9S mice, suggesting instability of the thrombus (Figure 7c). 


\section{Discussion}

In the present study, we addressed the question of the role of myosin and contractile activity in platelet functions. We established a mouse strain with megakaryocyte-restricted disruption of the MYH9 gene, leading to severe NMHC-IIA deficiency in platelets amounting to less than $3 \%$ of the wt platelets. The reason for the presence of residual very low amounts myosin could be due to an incomplete excision of the MYH9 exon 1 by the cre-recombinase in the megakaryocytes. Another possible explanation could be that the residual myosin reflects the long half-life of the NMHC-IIA synthesized before the time where the PF4 promoter becomes functional and promotes the expression of the Cre-recombinase. The appearance in the MYH9D platelets of a protein with a slightly lower molecular weight indicates that some synthesis from exon 1-deleted mRNA occurs. The presence of this protein in low amounts suggests that either the transcription or the traduction is not efficient, or that the truncated protein is unstable. In addition, the defect in NMHC-IIA expression led to a decrease in myosin RLC expression. This probably results from instability of the RLC in the absence of the heavy chain as already observed in Dictyostelium discoideum ${ }^{43}$ and more recently in Drosophila melanogaster ${ }^{42}$.

MYH9D mice presented a platelet phenotype closely resembling that of MYH9-related disorders in humans and consisting essentially of thrombocytopenia and large platelets, with an absence of agonist-induced platelet shape change ${ }^{18}$. However, due to its restriction to the megakaryocytic lineage, these mice lack additional defects observed in other tissues in MYH9-related diseases. The defect in protein expression in MYH9S platelets being more severe than the human defect, MYH9 $\triangle$ mice could represent an interesting model to study some aspects of MYH9-related diseases in addition to the role of myosin in platelet functions. 
The major observations were that MYH9D mice exhibited a considerable increase in the bleeding time and total absence of clot retraction. It is unlikely that the thrombocytopenia is the sole reason why MYH9S mice bled to death upon tail section. Indeed, busulfan-treated wt mice having thrombocytopenia in the same range as MYH9S mice displayed no such prolongation of the bleeding time. Moreover, in other severely thrombocytopenic mice such as cMpl, $\beta 1$ tubulin or GPIb $\beta$ knockout mice ${ }^{40,49,50}$ the bleeding tendency was likewise less pronounced. Hence our data suggest that altered platelet functions due to myosin deficiency are responsible for the defects.

The total absence of clot retraction may contribute to increase the bleeding time since impaired clot retraction has been shown to lead to rebleeding in several mouse models ${ }^{51,52}$. It is noteworthy that defective clot retraction has only been reported in a few MYH9 patients ${ }^{53}$ and one study mentioned normal clot retraction in a May-Hegglin subject who suffered from bleeding tendency ${ }^{54}$. One may speculate that some myosin activity are preserved in these patients, despite the presence of mutant forms of myosin IIA which are able to interact with the non mutated counterpart, thus "poisoning" the normal protein.

What makes the observation of increased bleeding time even more puzzling was that in vitro platelet aggregation and secretion were almost not altered in $M Y H 9 \Delta$ mice. The very modest impact of myosin deficiency on secretion was unexpected since early observations that the cytoskeleton directs granule centralization in platelets had long led to the speculation that actomyosin should provide a contractile force facilitating the release of granule contents ${ }^{55-57}$. Furthermore, inhibitors of myosin light chain kinase or Rho-kinase have been shown to block phosphorylation of the myosin light chain, a prerequisite for myosin activation, and to inhibit the release reaction, suggesting that actomyosin contraction is required for granule secretion ${ }^{5,12-15}$. Our results indicate that myosin contraction, while facilitating the release 
reaction following weak platelet stimulation, is in fact dispensable for platelet secretion when increasing agonist concentrations.

More unexpected, in view of the modest impact on platelet aggregation and secretion, was the alteration in thrombus formation both in vitro under high shear flow and in vivo. The disorganization of the thrombus in myosin-deficient mice is accompanied by an increase in emboli detaching from the thrombi. This effect on thrombus stability is most probably due to a decrease in aggregate stability under high shear forces that could result from both the absence of aggregate compaction and the defect in outside-in signaling. Indeed, aggregate compaction would be expected to allow the thrombus to resist shear forces and also to reduce the space between platelets, thus increasing local concentrations of released agonists. The capacity of platelets to remain in close contact to each other despite the shear forces rely on the engagement of integrins with their ligands, leading to signal transduction that reinforces the interactions between platelets. The $\alpha \operatorname{IIb} \beta 3$ integrin outside-in signaling resulting from fibrinogen binding leads to tyrosine phosphorylation of several proteins including the $\beta 3$ subunit itself, activation of the phosphoinositide metabolism, further cytoskeleton reorganization, enhancement of platelet activation and improved stability of the aggregates 47,58. Our results show that myosin plays a role in platelet integrin outside-in signaling as observed by a decrease in both $\operatorname{PtdIns}(3,4) \mathrm{P}_{2}$ accumulation and the $\beta 3$ subunit phosphorylation. Phosphorylation of $\beta 3$ allows direct interaction of the integrin with myosin. Platelets from DiYF mice, in which $\beta 3$ cannot be tyrosine phosphorylated, exhibit like MYH9S platelets moderately impaired aggregation and unstable aggregate formation in response to low concentrations of thrombin, together with impaired clot retraction ${ }^{52}$. Thus actomyosin contractility may be important to control the extent of outside-in signaling, maybe through integrin clustering and focal adhesion maturation as is observed in other cells ${ }^{59}$. The way myosin IIA regulates focal adhesion through stress fibers formation may also contribute 
to restrict lamellipodia extention in normal platelets following adhesion, similar to migrating cells where loss of NMHC-IIA-based contractility has been shown to relieve a restriction on protrusions extension ${ }^{60}$.

In conclusion, inactivation of MYH9 in the megakaryocytic lineage results in a severe deficiency in platelet myosin expression with a phenotype that partially resembles MYH9related diseases in humans, including thrombocytopenia and large platelets. In one hand, our results highlight the important role of myosin IIA in outside-in signaling, clot retraction and thrombus formation and organization which, in addition to thrombocytopenia, account for the deficient hemostasis observed in MYH9D mice. On the other hand, myosin plays no major role in platelet aggregation and secretion in suspension. Homozygous gene inactivation obtained in MYH9D mice differ from the genetic defects resulting from mutations in one MYH9 allele in patients with MYH9-related disorders. In these patients, expression of abnormal myosin is responsible for the pathology. Although this is probably the reason why patients have a less severe hemorrhagic syndrome than mice, the mechanisms described here nevertheless may explain part of the defects of hemostasis observed in the patients.

\section{Acknowledgments}

We thank Bernard Payrastre for critical reading of the manuscript. We thank Dominique Cassel, Patricia Laeuffer, Stéphanie Magnenat, Fabienne Proamer, Jean-Yves Rinckel, and Catherine Meyer for expert technical assistance, and J. N. Mulvihill for reviewing the English of the manuscript. 


\section{References}

1. Barkalow KL, Falet H, Hartwig JH. Dynamics of the platelet cytoskeleton. In: Gresele P, Page C, Fuster V, Vermylen J, eds. Platelets in thrombotic and non-thrombotic disorders. Cambridge: Cambridge University Press; 2002:93-103.

2. Gear ARL, Polanowska-Grabowska Rk. The platelet shape change. In: Gresele P, Page C, Fuster V, Vermylen J, eds. Platelets in thrombotic and non-thrombotic disorders. Cambridge: Cambridge University Press; 2002:319-337.

3. Fox JE. The platelet cytoskeleton. Thromb Haemost. 1993;70:884-893.

4. Fox JE. Cytoskeletal proteins and platelet signaling. Thromb Haemost. 2001;86:198213.

5. Suzuki Y, Yamamoto $\mathrm{M}$, Wada $\mathrm{H}$, et al. Agonist-induced regulation of myosin phosphatase activity in human platelets through activation of Rho-kinase. Blood. 1999;93:3408-3417.

6. Paul BZ, Daniel JL, Kunapuli SP. Platelet shape change is mediated by both calciumdependent and -independent signaling pathways. Role of p160 Rho-associated coiled-coilcontaining protein kinase in platelet shape change. J Biol Chem. 1999;274:28293-28300.

7. Bauer M, Retzer M, Wilde JI, et al. Dichotomous regulation of myosin phosphorylation and shape change by Rho-kinase and calcium in intact human platelets. Blood. 1999;94:1665-1672.

8. Klages B, Brandt U, Simon MI, Schultz G, Offermanns S. Activation of G12/G13 results in shape change and Rho/Rho-kinase-mediated myosin light chain phosphorylation in mouse platelets. J Cell Biol. 1999;144:745-754.

9. Daniel JL, Molish IR, Rigmaiden M, Stewart G. Evidence for a role of myosin phosphorylation in the initiation of the platelet shape change response. J Biol Chem. 1984;259:9826-9831.

10. Nachmias VT, Kavaler J, Jacubowitz S. Reversible association of myosin with the platelet cytoskeleton. Nature. 1985;313:70-72.

11. Tanaka K, Itoh K. Reorganization of stress fiber-like structures in spreading platelets during surface activation. J Struct Biol. 1998;124:13-41.

12. Lokeshwar VB, Bourguignon LY. The involvement of $\mathrm{Ca} 2+$ and myosin light chain kinase in collagen-induced platelet activation. Cell Biol Int Rep. 1992;16:883-897.

13. Nishikawa M, Tanaka T, Hidaka H. Ca2+-calmodulin-dependent phosphorylation and platelet secretion. Nature. 1980;287:863-865.

14. Saitoh M, Naka M, Hidaka H. The modulatory role of myosin light chain phosphorylation in human platelet activation. Biochem Biophys Res Commun. 1986;140:280287.

15. Watanabe $\mathrm{Y}$, Ito $\mathrm{M}$, Kataoka $\mathrm{Y}$, et al. Protein kinase C-catalyzed phosphorylation of an inhibitory phosphoprotein of myosin phosphatase is involved in human platelet secretion. Blood. 2001;97:3798-3805.

16. Suzuki-Inoue $\mathrm{K}$, Hughes $\mathrm{CE}$, Inoue $\mathrm{O}$, et al. Involvement of Src kinases and PLCgamma2 in clot retraction. Thromb Res. 2006.

17. Berg JS, Powell BC, Cheney RE. A millennial myosin census. Mol Biol Cell. 2001;12:780-794.

18. Noris P, Spedini P, Belletti S, Magrini U, Balduini CL. Thrombocytopenia, giant platelets, and leukocyte inclusion bodies (May-Hegglin anomaly): clinical and laboratory findings. Am J Med. 1998;104:355-360.

19. Seri M, Cusano R, Gangarossa S, et al. Mutations in MYH9 result in the May-Hegglin anomaly, and Fechtner and Sebastian syndromes. The May-Heggllin/Fechtner Syndrome Consortium. Nat Genet. 2000;26:103-105. 
20. Heath KE, Campos-Barros A, Toren A, et al. Nonmuscle myosin heavy chain IIA mutations define a spectrum of autosomal dominant macrothrombocytopenias: May-Hegglin anomaly and Fechtner, Sebastian, Epstein, and Alport-like syndromes. Am J Hum Genet. 2001;69:1033-1045.

21. Kunishima S, Matsushita T, Kojima $\mathrm{T}$, et al. Immunofluorescence analysis of neutrophil nonmuscle myosin heavy chain-A in MYH9 disorders: association of subcellular localization with MYH9 mutations. Lab Invest. 2003;83:115-122.

22. Pujol-Moix N, Kelley MJ, Hernandez A, Muniz-Diaz E, Espanol I. Ultrastructural analysis of granulocyte inclusions in genetically confirmed MYH9-related disorders. Haematologica. 2004;89:330-337.

23. Canobbio I, Noris P, Pecci A, Balduini A, Balduini CL, Torti M. Altered cytoskeleton organization in platelets from patients with MYH9-related disease. J Thromb Haemost. 2005;3:1026-1035.

24. Heynen MJ, Blockmans D, Verwilghen RL, Vermylen J. Congenital macrothrombocytopenia, leucocyte inclusions, deafness and proteinuria: functional and electron microscopic observations on platelets and megakaryocytes. $\mathrm{Br} \mathrm{J}$ Haematol. 1988;70:441-448.

25. Lusher JM, Barnhart MI. Congenital disorders affecting platelets. Semin Thromb Hemost. 1977;4:123-186.

26. Jantunen E. Inherited giant platelet disorders. Eur J Haematol. 1994;53:191-196.

27. D'Apolito M, Guarnieri V, Boncristiano M, Zelante L, Savoia A. Cloning of the murine non-muscle myosin heavy chain IIA gene ortholog of human MYH9 responsible for May-Hegglin, Sebastian, Fechtner, and Epstein syndromes. Gene. 2002;286:215-222.

28. Matsushita T, Hayashi H, Kunishima S, et al. Targeted disruption of mouse ortholog of the human MYH9 responsible for macrothrombocytopenia with different organ involvement: hematological, nephrological, and otological studies of heterozygous KO mice. Biochem Biophys Res Commun. 2004;325:1163-1171.

29. Franke JD, Dong F, Rickoll WL, Kelley MJ, Kiehart DP. Rod mutations associated with MYH9-related disorders disrupt nonmuscle myosin-IIA assembly. Blood. 2005;105:161169.

30. Deutsch S, Rideau A, Bochaton-Piallat ML, et al. Asp1424Asn MYH9 mutation results in an unstable protein responsible for the phenotypes in May-Hegglin anomaly/Fechtner syndrome. Blood. 2003;102:529-534.

31. Pecci A, Noris P, Invernizzi R, et al. Immunocytochemistry for the heavy chain of the non-muscle myosin IIA as a diagnostic tool for MYH9-related disorders. Br J Haematol. 2002;117:164-167.

32. Conti MA, Even-Ram S, Liu C, Yamada KM, Adelstein RS. Defects in cell adhesion and the visceral endoderm following ablation of nonmuscle myosin heavy chain II-A in mice. J Biol Chem. 2004;279:41263-41266.

33. Tiedt R, Schomber T, Hao-Shen H, Skoda RC. Pf4-Cre transgenic mice allow generating lineage-restricted gene knockouts for studying megakaryocyte and platelet function in vivo. Blood. 2006.

34. Peng J, Friese P, Heilmann E, George JN, Burstein SA, Dale GL. Aged platelets have an impaired response to thrombin as quantitated by P-selectin expression. Blood. 1994;83:161-166.

35. Leon C, Hechler B, Freund M, et al. Defective platelet aggregation and increased resistance to thrombosis in purinergic $\mathrm{P} 2 \mathrm{Y}(1)$ receptor-null mice. $\mathrm{J}$ Clin Invest. 1999; 104:1731-1737.

36. McCarty OJ, Larson MK, Auger JM, et al. Rac1 is essential for platelet lamellipodia formation and aggregate stability under flow. J Biol Chem. 2005;280:39474-39484. 
37. Kauffenstein G, Bergmeier W, Eckly A, et al. The P2Y(12) receptor induces platelet aggregation through weak activation of the alpha(IIb)beta(3) integrin--a phosphoinositide 3kinase-dependent mechanism. FEBS Lett. 2001;505:281-290.

38. Payrastre B. Phosphoinositides: lipid kinases and phosphatases. Methods Mol Biol. 2004;273:201-212.

39. Strassel C, Nonne C, Eckly A, et al. Decreased thrombotic tendency in mouse models of the Bernard-Soulier syndrome. Arterioscler Thromb Vasc Biol. 2007;27:241-247.

40. Strassel C, Nonne C, Eckly A, et al. Decreased thrombotic tendency in mouse models of the Bernard-Soulier syndrome. Arterioscler Thromb Vasc Biol. 2006; in press.

41. Gross S, Tilly P, Hentsch D, Vonesch JL, Fabre JE. Vascular wall-produced prostaglandin E2 exacerbates arterial thrombosis and atherothrombosis through platelet EP3 receptors. J Exp Med. 2007;204:311-320.

42. Franke JD, Boury AL, Gerald NJ, Kiehart DP. Native nonmuscle myosin II stability and light chain binding in Drosophila melanogaster. Cell Motil Cytoskeleton. 2006;63:604622.

43. Knecht DA, Loomis WF. Developmental consequences of the lack of myosin heavy chain in Dictyostelium discoideum. Dev Biol. 1988;128:178-184.

44. Limouze J, Straight AF, Mitchison T, Sellers JR. Specificity of blebbistatin, an inhibitor of myosin II. J Muscle Res Cell Motil. 2004;25:337-341.

45. Straight AF, Cheung A, Limouze J, et al. Dissecting temporal and spatial control of cytokinesis with a myosin II Inhibitor. Science. 2003;299:1743-1747.

46. Guinebault C, Payrastre B, Racaud-Sultan C, et al. Integrin-dependent translocation of phosphoinositide 3-kinase to the cytoskeleton of thrombin-activated platelets involves specific interactions of p85 alpha with actin filaments and focal adhesion kinase. J Cell Biol. 1995;129:831-842.

47. Payrastre B, Missy K, Trumel C, Bodin S, Plantavid M, Chap H. The integrin alpha $\mathrm{IIb} /$ beta 3 in human platelet signal transduction. Biochem Pharmacol. 2000;60:1069-1074.

48. Nonne C, Lenain N, Hechler B, et al. Importance of platelet phospholipase Cgamma2 signaling in arterial thrombosis as a function of lesion severity. Arterioscler Thromb Vasc Biol. 2005;25:1293-1298.

49. Bunting S, Widmer R, Lipari $\mathrm{T}$, et al. Normal platelets and megakaryocytes are produced in vivo in the absence of thrombopoietin. Blood. 1997;90:3423-3429.

50. Schwer HD, Lecine P, Tiwari S, Italiano JE, Jr., Hartwig JH, Shivdasani RA. A lineage-restricted and divergent beta-tubulin isoform is essential for the biogenesis, structure and function of blood platelets. Curr Biol. 2001;11:579-586.

51. Goschnick MW, Lau LM, Wee JL, et al. Impaired "outside-in" integrin alphaIIbbeta3 signaling and thrombus stability in TSSC6-deficient mice. Blood. 2006;108:1911-1918.

52. Law DA, DeGuzman FR, Heiser P, Ministri-Madrid K, Killeen N, Phillips DR. Integrin cytoplasmic tyrosine motif is required for outside-in alphallbbeta3 signalling and platelet function. Nature. 1999;401:808-811.

53. Godwin HA, Ginsburg AD. May-Hegglin anomaly: a defect in megakaryocyte fragmentation? Br J Haematol. 1974;26:117-128.

54. Volpe E, Cuccurullo L, Valente A, Jori GP, Buonanno G. The May-Hegglin anomaly. Further studies on leukocyte inclusions and platelet ultrastructure. Acta Haematol. 1974;52:238-247.

55. Painter RG, Ginsberg MH. Centripetal myosin redistribution in thrombin-stimulated platelets. Relationship to platelet Factor 4 secretion. Exp Cell Res. 1984;155:198-212.

56. Gerrard JM, Israels SJ, Friesen LL. Protein phosphorylation and platelet secretion. Nouv Rev Fr Hematol. 1985;27:267-273. 
57. White JG, Gerrard JM. Recent advances in platelet structural physiology. Suppl Thromb Haemost. 1978;63:49-60.

58. Phillips DR, Prasad KS, Manganello J, Bao M, Nannizzi-Alaimo L. Integrin tyrosine phosphorylation in platelet signaling. Curr Opin Cell Biol. 2001;13:546-554.

59. Chrzanowska-Wodnicka M, Burridge K. Rho-stimulated contractility drives the formation of stress fibers and focal adhesions. J Cell Biol. 1996;133:1403-1415.

60. Sandquist JC, Swenson KI, Demali KA, Burridge K, Means AR. Rho kinase differentially regulates phosphorylation of nonmuscle myosin II isoforms A and B during cell rounding and migration. J Biol Chem. 2006;281:35873-35883. 
Table 1: Percentage 5 HT secretion in wt and MYH9D mice

\begin{tabular}{llc}
\hline Agonists & control $(\mathrm{wt})$ & MYH9S \\
\hline Thrombin $(1 \mathrm{U} / \mathrm{mL})$ & 100 & $84.0 \pm 10$ \\
Thrombin $(0.03 \mathrm{U} / \mathrm{mL})$ & $10.7 \pm 3.8$ & $1.2 \pm 0.91$ \\
Collagen $(100 \mu \mathrm{g} / \mathrm{mL})$ & 100 & $93.0 \pm 2.5$ \\
Collagen $(5 \mu \mathrm{g} / \mathrm{mL})$ & $79.7 \pm 1.3$ & $62.3 \pm 3.8^{\square}$ \\
U46619 $(1 \mu \mathrm{M})$ & $24.0 \pm 0.6$ & $2.7 \pm 1.3^{\dagger}$
\end{tabular}

Mean \pm sem of 3 independent experiments, ${ }^{\square} \mathrm{p}<0.05,{ }^{\dagger} \mathrm{p}<0.01$, Student Paired t-test. 


\section{Figure Legends}

Figure 1. Generation of a platelet-specific MYH9 knock-down mouse strain exhibiting myosin deficiency. (a) ES cells recombined with the floxed allele were injected into blastocysts to produce chimeric floxed mice (i). Deletion of the MYH9 exon1 (MYH9A) was obtained by exposing the floxed allele to in vivo cre-recombinase expression (ii). (b) Western blot showing NMCH-IIA expression in several tissues from MYH9D mice (-/-) and control mice (+/+). An identical amount of protein lysate for control or MYH9S platelets was loaded in each lane, as shown by the similar levels of actin. (c) Upper panel: Western blot performed with increasing amounts of lysate from control (+/+) and MYH9S (-/-) platelets (numbers indicate the amount in $\mu \mathrm{g}$ of protein loaded on the gel), showing the residual myosin expressed in platelets (large grey arrow) and exon 1-deleted myosin (small black arrow). Lower panel: Western blot showing the regulatory light chain (RLC) expression in control and MYH9S platelets. (d) The entire population of platelets displayed decreased myosin content in MYH9A, as revealed by confocal immunofluorescence microscopy (one image representative of 3 independent mice). Bars $2 \mu \mathrm{m}$.

Figure 2. Platelet counts and ultrastructure. (a) MYH9D mice exhibited thrombocytopenia. The mean is represented in the figure $(n=17-18)$. (b-c) Heterogeneity in platelet size as observed both by transmission electron microscopy (left panels) and by flow cytometry (right panels, showing representative dot plots of whole blood: FSC, forward scatter; SSC, side scatter; $\alpha_{\mathrm{IIb}} \beta_{3}$-positive platelets are visualized by red dots). Control (b) and MYH9S (c) mouse platelets, bars $2 \mu \mathrm{m}$. (d) Higher magnification of a MYH9S platelet showing the highly developed rough endoplasmic reticulum. Bar $2 \mu \mathrm{m}$. 
Figure 3. Bleeding time and clot retraction. (a) MYH9D mice had an increased bleeding time. Points indicate the time required for the arrest of bleeding and when necessary bleeding was stopped manually after $10 \mathrm{~min}$. Control wt mice, grey circles, $\mathrm{n}=13$; heterozygous mice, open squares, $n=14$; MYH9 $\Delta$ mice, black triangles, $n=21$; wt mice treated with busulfan to achieve thrombocytopenia comparable to that of MYH9 $\Delta$ mice, grey triangles, $n=20$. (b) Clot retraction was totally abolished in PRP from MYH9S mice, while it was delayed in heterozygous mice. The photograph corresponds to a 2 and 5-hour reaction in cPRP adjusted to $3.10^{5}$ platelets $/ \mu \mathrm{L}$ and treated with $10 \mathrm{U} / \mathrm{mL}$ thrombin and is representative of 3 experiments.

Figure 4. Platelet aggregation is preserved in MYH9ऽ mice despite absence of initial shape change. (a) Platelet aggregation in response to ADP, thrombin, collagen and U46619 were barely impaired in MYH9S mice (numbers correspond to the concentration of agonist). The initial platelet contraction responsible for a transient decrease in light transmission (circled) was absent in MYH9D platelets. Tracings are representative of at least 3 experiments.

(b) Shape change was evaluated in the aggregometer after stimulation of washed platelets with $5 \mu \mathrm{M}$ ADP in the absence of fibrinogen and the presence of Eptifibatid. Shape change was visualized by scanning electron microscopy and by the decrease in light transmission (inset), representative of 3 independent experiments. Bars $2 \mu \mathrm{m}$.

Figure 5. Defective stress-fiber formation during spreading of MYH9D platelets. Platelets were pretreated with thrombin $(1 \mathrm{U} / \mathrm{mL})$ and allowed to adhere for $45 \mathrm{~min}$ to fibrinogencoated coverslips. Actin filaments were visualized (a) by confocal fluorescence microscopy 
after phalloidin-AF 488 labeling (bars $25 \mu \mathrm{m}$, inset $7.5 \mu \mathrm{m}$ ) and (b) by SEM after Triton X100 permeabilization (bars $2 \mu \mathrm{m}$ ). Representative of 3 experiments.

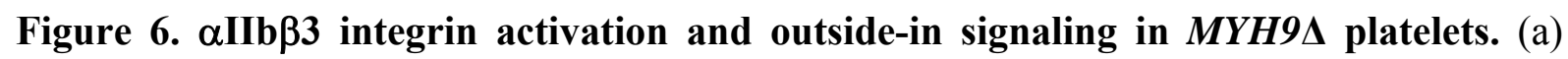
Flow cytometry experiments showing integrin $\alpha_{\mathrm{IIb}} \beta_{3}$ activation as revealed by Jon/A-PE (left panel) or fibrinogen (right panel) labeling following platelet activation by thrombin (thr, $1 \mathrm{U} / \mathrm{mL}$ ) or collagen (coll, $100 \mu \mathrm{g} / \mathrm{mL}$ ) in the absence of agitation. The amount of activated integrin is indicated by the geometric mean of the relative fluorescence intensity, in arbitrary units. Grey and black bars represent control and MYH9S platelets, respectively; mean \pm standard error mean (sem), $n=3$ experiments. (b) Western blots showing phosphorylation of integrin $\beta 3$ at Y773 (upper panel) during stimulation of platelets suspension by thrombin $(1 \mathrm{U} / \mathrm{mL})$ for up to $3 \mathrm{~min}$ in the aggregometer. Identical protein loading was checked by reblotting with an anti- $\beta 3$ antibody (lower panel). Blots are representative of 2 experiments. (c) PtdIns $(3,4) \mathrm{P}_{2}$ synthesis following thrombin $(1 \mathrm{U} / \mathrm{mL})$ or collagen $(10 \mu \mathrm{g} / \mathrm{mL})$ stimulation upon 2 minutes. Values have been normalized against total polyphosphoinositides and the results are presented as fold increase compared to non stimulated platelets $( \pm$ sem, $n=3$ independent experiments).

Figure 7. Defective thrombus formation in vitro and in vivo. (a) Whole blood from busulfan-treated wt mice $(+/+)$ or MYH9D mice (-/-) was anticoagulated with hirudin (100 $\mathrm{U} / \mathrm{mL}$ ) and perfused through collagen-coated glass capillaries at a shear rate of $3000 \mathrm{~s}^{-1}$. Scanning electron microscopy imaging was performed after 2 min perfusion and images are representative of 3 experiments. Bars $20 \mu \mathrm{m}$ (upper panels) and $5 \mu \mathrm{m}$ (lower panels). (b) $\mathrm{FeCl}_{3}$-induced injury was performed in the carotid of busulfan-treated wt mice $(+/+)$ or MYH9D mice (-/-) and the thrombus growth was video recorded. Images are representative of 
8 mice, at time $600 \mathrm{~s}$ following injury (original magnification X45). (c) Time courses of the embolus surface area measured by the fluorescence passing through the region of interest (white square in the insert), downstream of the thrombus. Busulfan-treated mice (grey curve) and MYH9D mice (black curve); $\mathrm{n}=8, \mathrm{p}<0.0001$ (Student Paired t-test). 
Figure 1

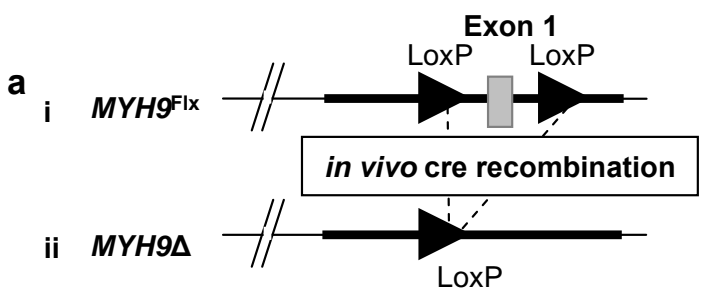

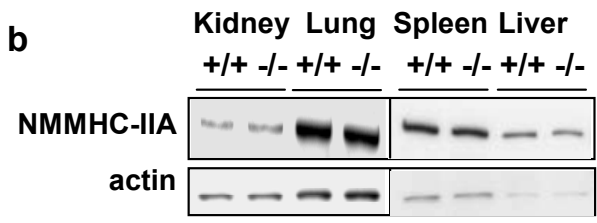

c
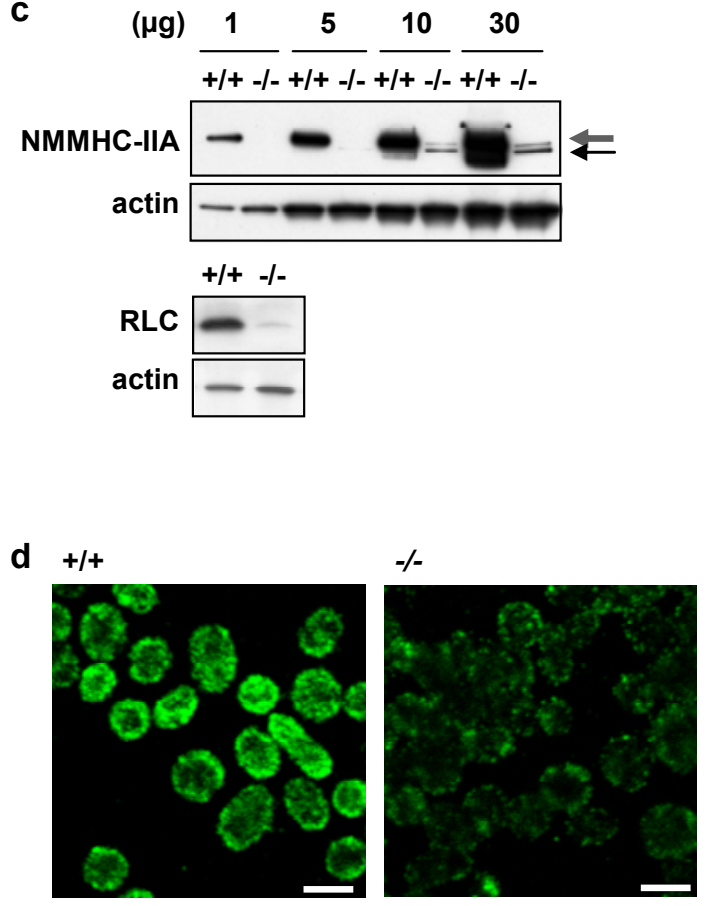
Figure 2

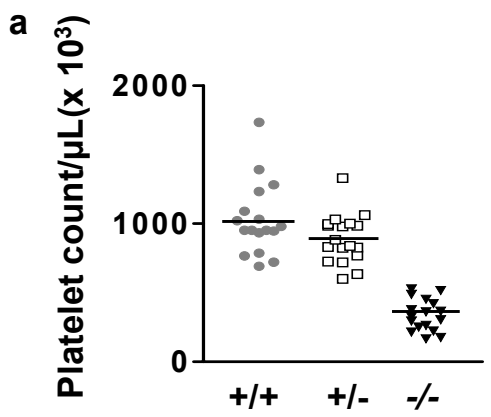

b

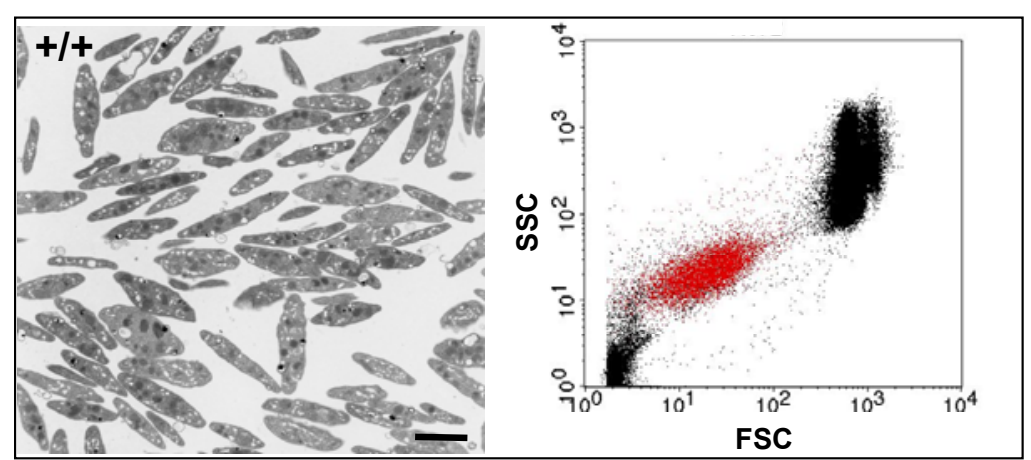

c

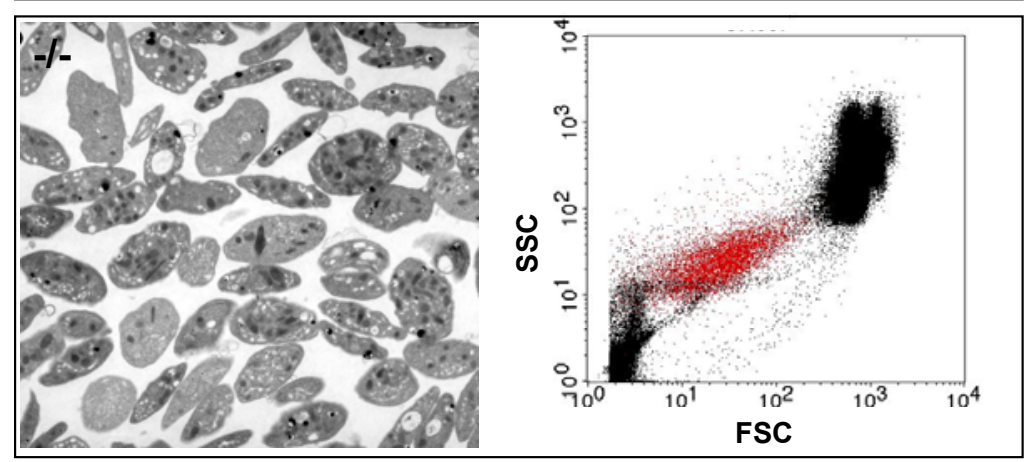

d

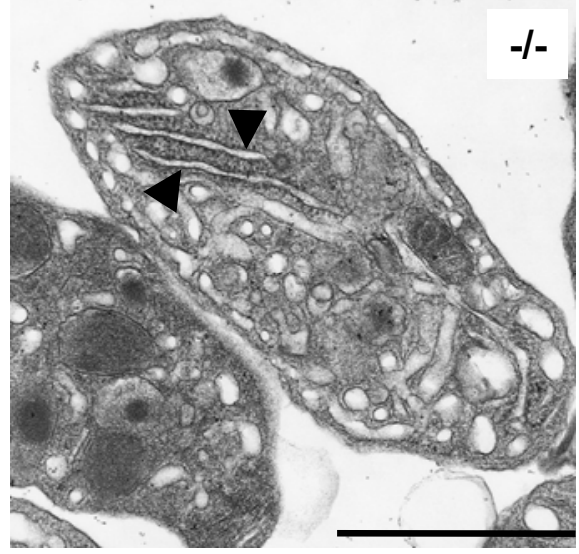


Figure 3

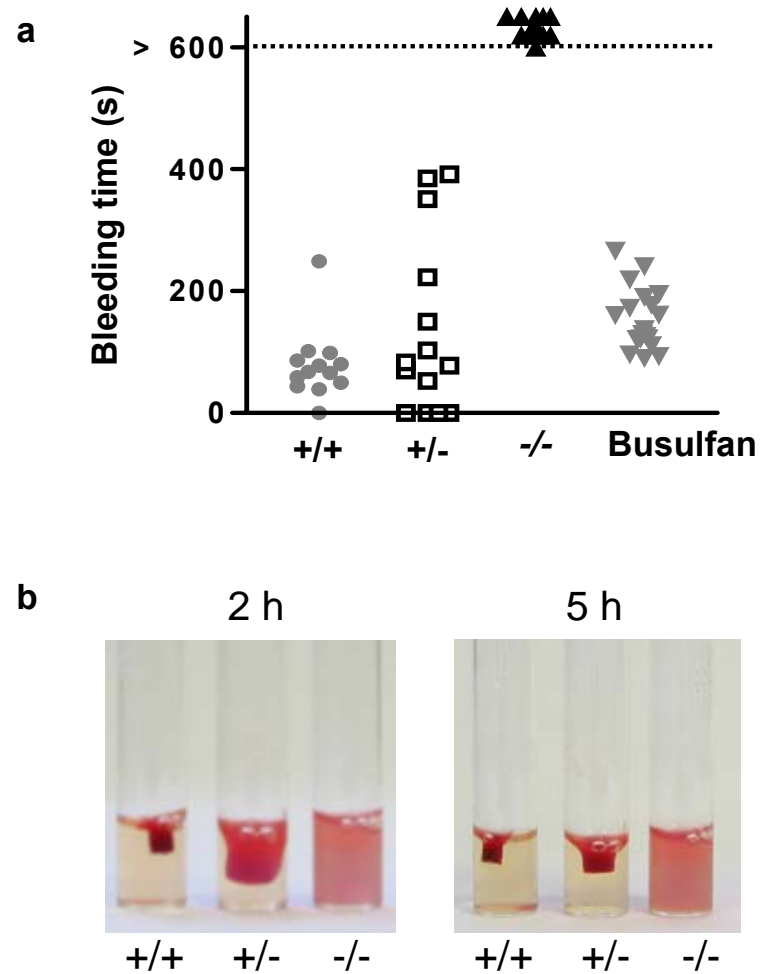


Figure 4

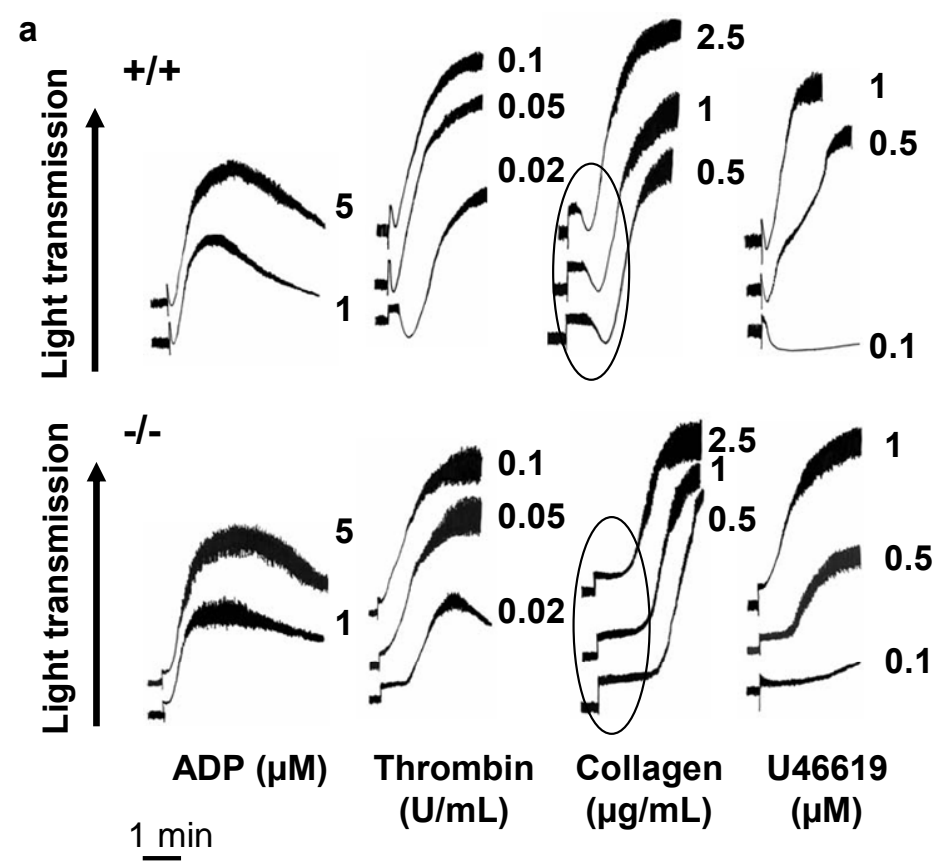

b

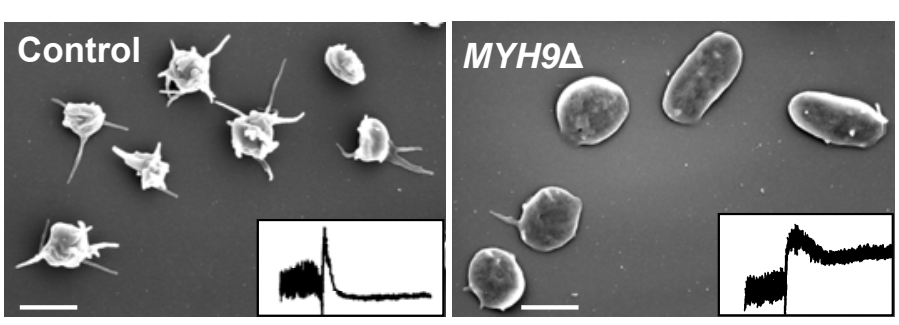


Figure 5
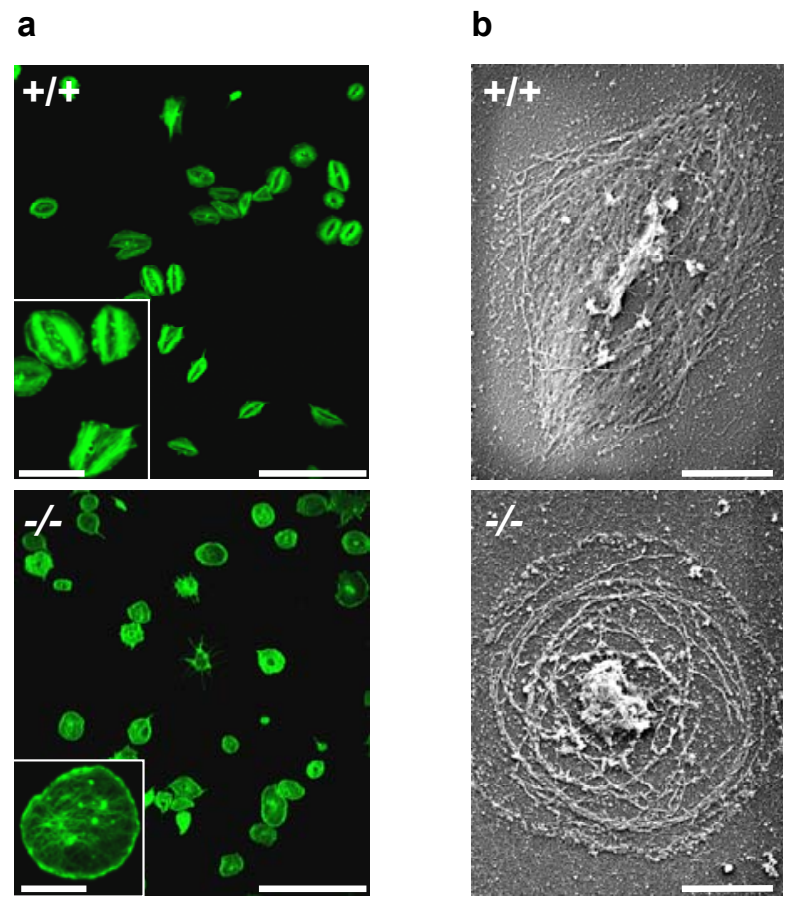
Figure 6
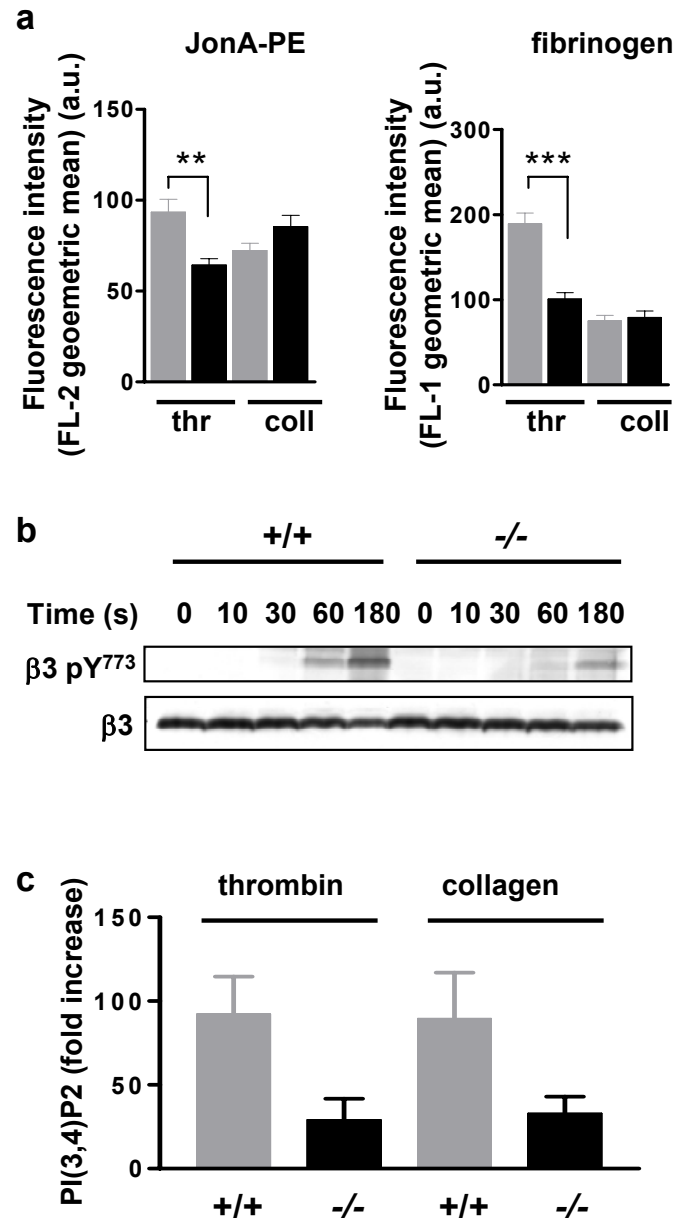
Figure 7

a

$+/+$

-/-

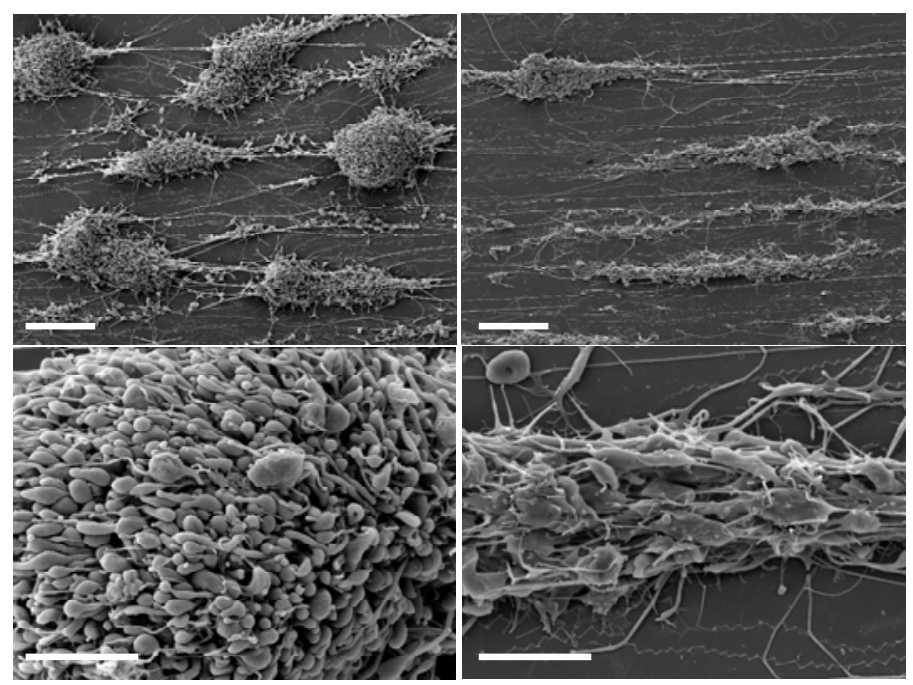

b
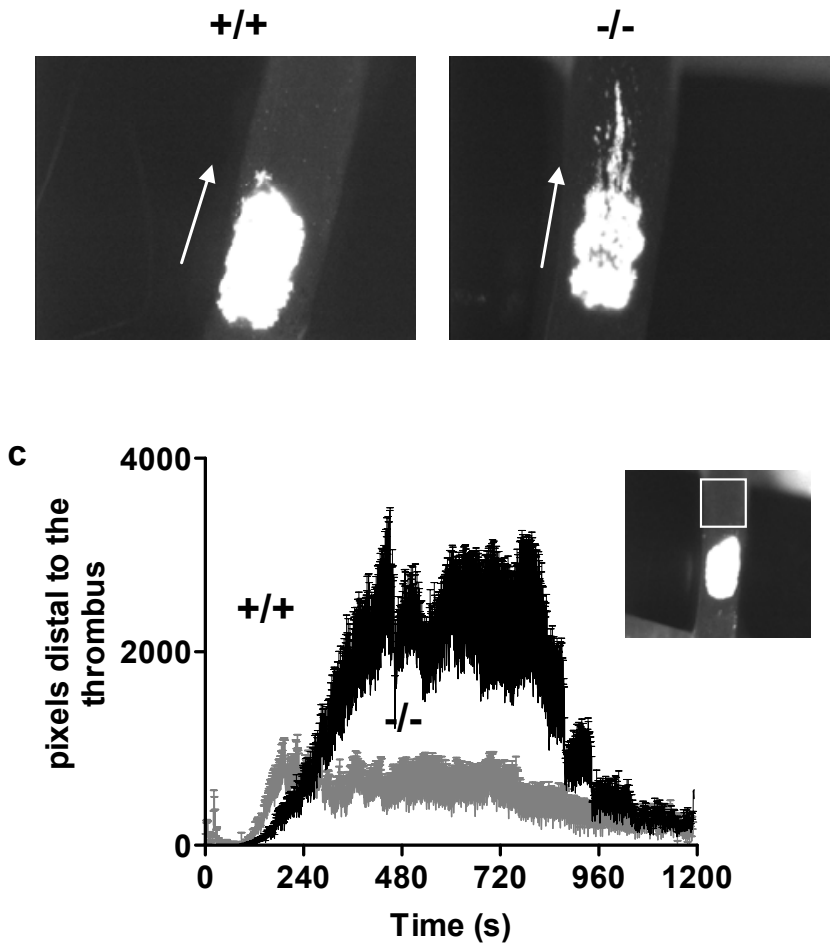